
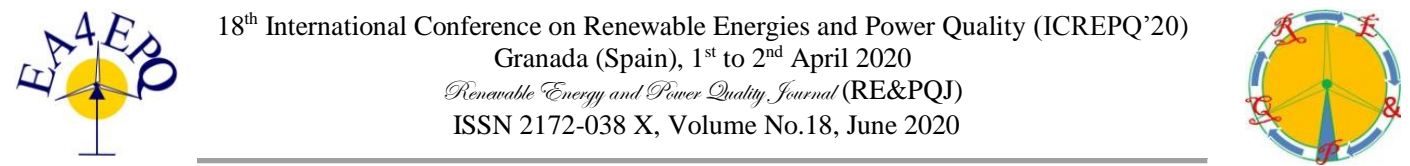

\title{
Control and Application of Grid-Connected Cascaded H-Bridge PV Inverters
}

\author{
Jeyraj Selvaraj ${ }^{1}$, Aamir Amir ${ }^{1}$, Asim Amir ${ }^{1}$ and Nasrudin Abd Rahim ${ }^{1}$ \\ ${ }^{1}$ UM Power Energy Dedicated Advanced Centre (UMPEDAC) \\ Level 4, Wisma R\&D, University of Malaya \\ Jalan Pantai Baharu, 59990 Kuala Lumpur, Malaysia \\ Phone/Fax number:+603 2246 3251, e-mail: jeyraj@um.edu.my, nasrudin@um.edu.my
}

\begin{abstract}
In the case of grid-tied PV inverters, in general terms, the quality of current remains the determinant of the power quality, as voltage of a PV inverter cannot be controlled. Therefore, the current control strategy carries a prime importance for a grid-tied system. Low levels of harmonic distortion, increased dynamic response, and the DC-link voltage regulation are the fundamentals requirements that must be satisfied by a grid-tied system. Here, the entire output produced by the PV systems largely depends on the current-control technique employed. This paper offers an overview of various current control schemes and presents a novel current control technique for grid-connected cascaded H-bridge PV inverters. This control technique is implemented on a $\pi(\mathrm{Pi})$ type thriteen level cascaded $\mathrm{H}$-bridge (PiCHB) PV inverter.
\end{abstract}

Key words. Grid-connected, current control techniques, cascaded H-Bridge, Pi-type.

\section{Introduction}

Across the entire globe, an increased level of energy consumption is expected to increase [1]. In the near future, fossil energy is predicted to be insufficient to meet the increasing energy demands [2]. Therefore, the research interests in the fields of renewable energy and energy technology have seen a dramatic increase [3]. As a feasible renewable energy option, solar energy, has been the favoured choice due to its abundance and reliablity. Considering the amount of electricity generation from renewable energy soruces, PV energy yield is predicted to increase [4].

The prime aim of any grid-tied PV energy system is mainly to transmit the optimum amount of solar energy to the grid [5]. Here, a current controller comes in as the most important for the energy transmission, as injection of the current into to the grid remains the most imporatant task of the control. In addition, reduced total harmonic distortion (THD), better current quality and imporved efficiency are ought to be assured by the control system employed. Various control strategies have been utilized by many researchers [6-16].

This paper offers an overview of different current control schemes and presents a novel current control technique for grid-connected PV systems employing cascaded $\mathrm{H}$ bridge PV inverters.

\section{Overview of Current Control Schemes}

Inverter's output-voltage modulation principle is often achieved by comparing actual measured current igrid with desired reference iref (see Figure 1). Error signal $\delta$ is used by the current controller to either provide the modulator with control signal $\mathrm{Vc}$ or to directly generate switching states $\mathrm{Si}$ for the converter's power devices (in which case the current controller and the modulator are assumed to be a single block).

Major strategies for regulating output current of the VSI are hysteresis, ramp comparison, and predictive current control. Other current control methods are sliding mode, fuzzy, neural network, etc.

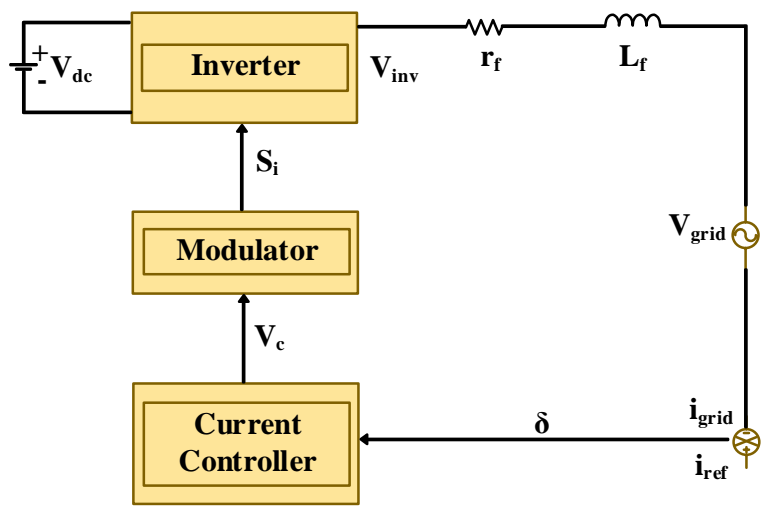

Figure 1: Basic current control scheme

\section{A. Hyteresis current control}

Among control methods, hysteresis current control (HCC) is more-easily implemented; offering simpler computation, and the current control is robust against changes to the source parameters $[8,9]$. HCC has been implemented in single-phase grid-connected inverter with full-bridge topology [7]. In HCC's control of Voltage 
source inverter (VSI), measured current is instantaneously compared with reference-current signal.

For HCC of the inverter in Figure 2, current-error signal $\delta$ is compared with the hysteresis band of Figure 3. When $\delta$ crosses upper boundary $+h$, switches $\mathrm{S} 1$ and S4 turn ON, $\mathrm{S} 2$ and $\mathrm{S} 3$ turn OFF. When $\delta$ crosses lower boundary $-h$, switches S1 and S4 turn OFF, and S2 and S3 turn ON; delays and dead times are neglected. Figure 3 is the hysteresis modulator.

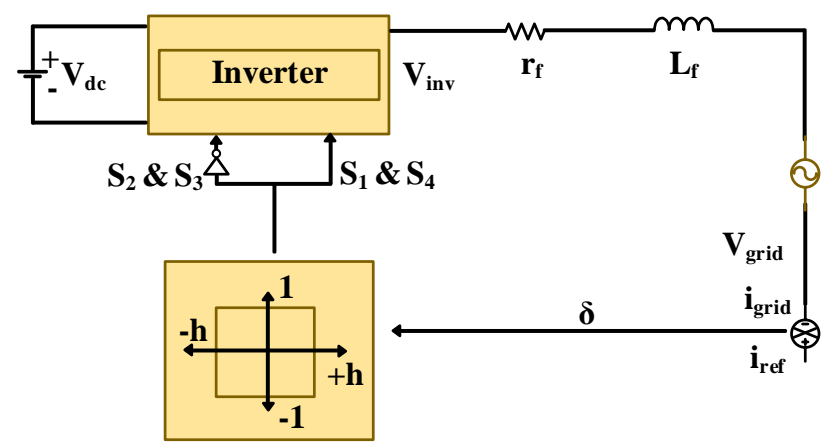

Figure 2: HCC with single-band for single-phase grid-connected inverter

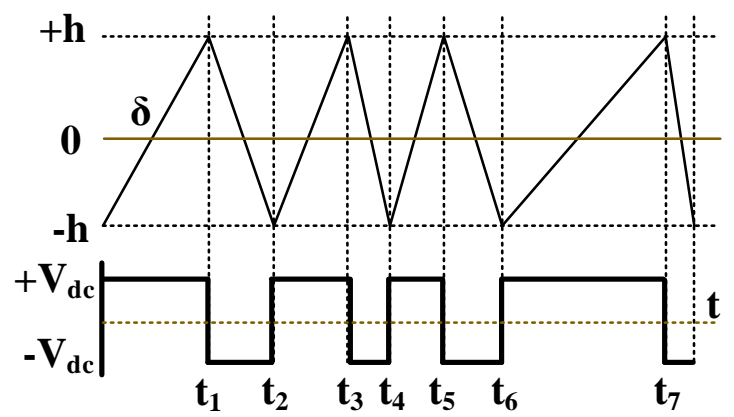

Figure 3: Hysteresis modulator

\section{B. Linear Current Control}

Linear current controllers are classified as ramp comparison controllers, stationary vector controllers, or synchronous vector controllers. Ramp comparison compares current errors to triangular wave to generate inverter-firing signals [10]. A single-phase full bridge grid connected inverter that uses ramp-comparison current controller with PI error compensators and a fixedfrequency triangular carrier to generate gate signals for the converter power switches has been described [11]. The phase current error $\delta$ is fed to PI controller, and Vc as the output from controller is compare with the triangular carrier of the pulse-width modulator as shown in Figure 4.

Figure 5 is the inverter's output voltage from comparing the control signal Vc with the triangular carrier Vcarrier . If the control signal is higher than the triangular signal, the switches activate, applying $\mathrm{Vdc}$ to the output. If the control signal is lower than the carrier (triangular) signal, output voltage $-\mathrm{Vdc}$ is produced.

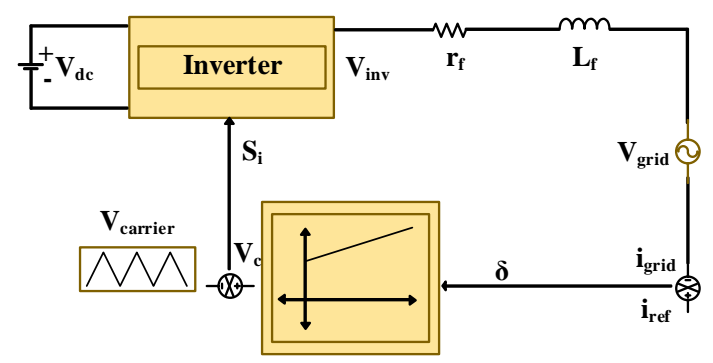

Figure 4: Ramp-comparison current-control scheme

Points of intersection define switching instants of the power switches. This keeps the switching frequency constant, because the carrier operates on fixed frequency.

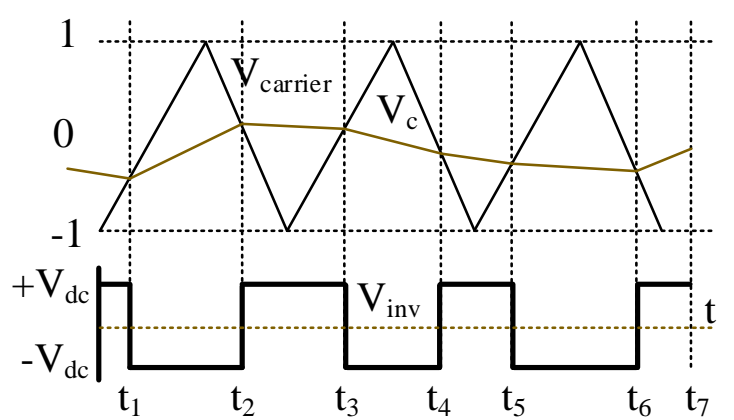

Figure 5: Inverter output voltage achieved via comparison between control signal $\mathrm{Vc}$ and triangular carrier voltage Vcarrier

The integral part of the PI compensator reduces errors at low frequency. Proportional gain and zero placement are related here. The maximum slope of the control signal Vc should never exceed the slope of the triangular signal.

\section{Predictive Current Control}

Predictive controllers compute the inverter voltages required to force the measured currents into following the reference current $[12,15,16]$. The method has potential to achieve more-accurate current control with minimum distortion and minimum harmonic noise, though it needs more calculations and requires good knowledge of system parameters. Powerful, low-cost DSP-based microcontrollers have made implementation of predictive strategies into digital controllers particularly popular recently.

Predictive current controller's basic idea is a fast and accurate control loop that selects among all possibilities the optimum control action fulfilling predefined criteria [13]. The decision is based on knowledge of actual measurements of variable and load parameters.

Figure 6 shows the structure of a typical predictive current controller. The "Load Model" block provides actual load states to "Prediction and Decision" (considered the heart of a predictive control system). Comparison of the actual states and the reference bases selection of the optimum switching state on the criteria decided upon (e.g., minimum swtichihng frequency, minimum response time, minimum current distortion) [14]. 


\section{Proposed Current Control Technique Implemented on PiCHB}

Figure 7 presents the proposed current control for the gridconnected PV system. Here a two stage PV system is taken into consideration. The first block in Figure 7 represents the PV modules serially-connected to form a PV string for each cascade. The next block represents the boost converters, involving an inductor, preceded by the DCLink capacitors. The filter inductor is connected after the inverter. Usually a step up transformer is employed to boost the inverter output voltage to the grid voltage.

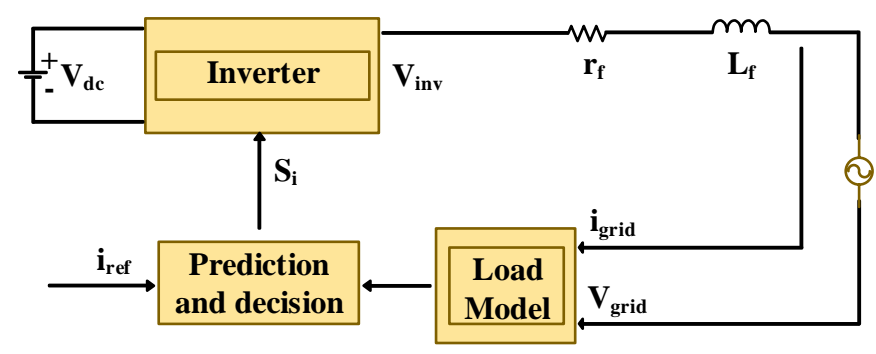

Figure 6: Basic structure of predictive current control

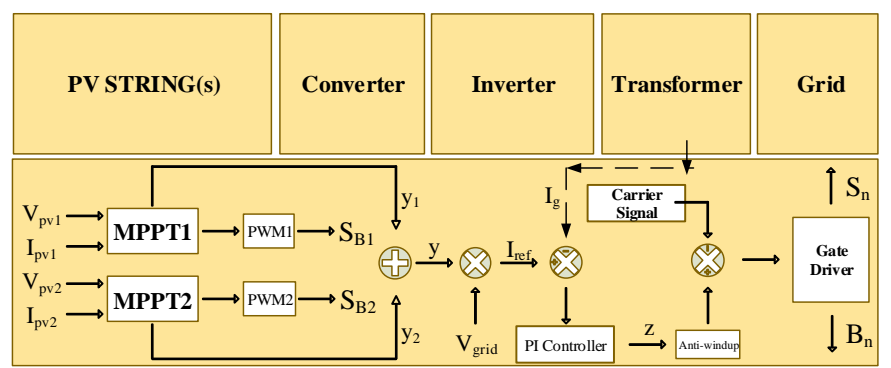

Figure 7: Simulation setup of the PiCHB grid-connected PV inverter

In order to extract the maximum power from the PV modules a Maximum Power Point Tracking (MPPT) technique had been employed. The Proportional (P) controller was utilized for the voltage-regulating boost converter. Proportional Integrator (PI) controller was applied to the current controller.

An adaptive step size MPPT scheme as presented in [17] had been utilized separately for each cascade. This adaptive step MPPT decreased complexity, offered better transient response, and responded to dynamic changes in ambient irradiance in an efficient manner. In addition, this MPPT technique offered simple implementation by eradicating the division complexity of incremental conductance (INC) by transforming it into Modified Incremental Conductance (mINC).

As displayed in Figure 7, for this current control, grid current, Ig, is considered to be the feedback signal in order to be compared with the reference current, Iref, where Iref $=\mathrm{Vg} * \mathrm{y}$. Here, the grid voltage, $\mathrm{Vg}$, is transformed into the reference signal by multiplying it with the variable $y$, where $\mathrm{y}$ is obtained from the indirect MPPT technique employed.

This control technique was applied to the two stage PV system employing PiCHB inverters. The PiCHB inverters comprised of two H-bridges, two $\pi$-Type bidirectional switches, and six voltage-dividing capacitors. Each cascade possessed one $\pi$-type bidirectional switch and three capacitors. Reduced switching losses, diodes, gate drives and number of switches made the PiCHB topology an effective choice. In order to boost the voltage to the grid requirements, two Dc-Dc boost converters were utilized. The converters were placed between the PV arrays and each cascade of the inverter. A filtering inductance $L_{f}$ was employed at the output.

By utilizing a suitable PWM control for the cascaded inverter, thirteen output-voltage levels $(2 \mathrm{Vdc}, 5 \mathrm{Vdc} / 3$, $4 \mathrm{Vdc} / 3, \mathrm{Vdc}, 2 \mathrm{Vdc} / 3, \mathrm{Vdc} / 3,0,-\mathrm{Vdc} / 3,-2 \mathrm{Vdc} / 3,-\mathrm{Vdc}$, $-4 \mathrm{Vdc} / 3,-5 \mathrm{Vdc} / 3,-2 \mathrm{Vdc}$ ) were produced. Here, twelve reference signals, operating at equivalent amplitude, frequency and phase, except an offset value were intersected against the carrier. Here, switches of the $\mathrm{H}$ bridge would operate at fundamental frequency, whereas, rest of the Switches within the PiCHB, including the bidirectional common emitter switches would opérate at the frequency of the carrier.

Five SIEMENS SP75 modules were serially-connected for each cascade. The boost converters had an inductor $\mathrm{L}=3 \mathrm{mH}$. Each cascaded utilized DC-Link capacitors C1, $\mathrm{C} 2$ and $\mathrm{C} 3$ of $2200 \mu \mathrm{F}$ each. The filter inductor was $\mathrm{L}=5 \mathrm{mH}$. The grid-frequency was $50 \mathrm{~Hz}$ and the $\mathrm{AC}$ voltage rms was $240 \mathrm{~V}$. Extraction of maximum power from the PV modules was by mINC method. Proportional Integrator (PI) controller was applied to the current controller, with proportional gain $\mathrm{Kp}=10$ and integrator gain $\mathrm{Ki}=0.1$.

\section{Simulation Results}

In order to simulate the proposed current control scheme a two stage grid connected PV system with a boost converter and a Pi-type multilevel inverter has been utilized. Here, a PV-module model representative of PVmodule characteristics was also employed. Where, I-V and $\mathrm{P}-\mathrm{V}$ curves were simulated on MATLAB, for various irradiances. The SIEMENS SP75 module was utilized, in the MATLAB simulation and experiment prototype. Table 1 indicates the SIEMENS SP75 PV module's characteristics.

As, for grid current injection the dc-bus voltage must always be kept higher than $\sqrt{2}$ of $V_{\text {gridl }}$, two boost converters, one with each cascade and a transformer has been utilized to step up the inverter voltaje Vin. Figure 8 shows the output voltage and output current of the Pitype inverter, which generated an eleven-level output voltage waveform at the output terminal, or, when the modulation index was above 0.667 but below 0.834 , with 
pre-filtered sinusoidal voltage and current at the load terminal. Here, the Modulation Index was set to be 0.75 . Only when the inverter voltage was greater than the grid voltage, the power was injected into the grid.

Figure 9 shows the time response of the inverter's output voltage before filter, inverter's output voltage after filter, grid voltage and pre-transformer output current for MPPT mode.

\section{Table 1: Characteristics of the PV module}

\begin{tabular}{|l|l|}
\hline \multicolumn{2}{|l|}{ Model: SIEMENS SP75 } \\
\hline Parameter & Value \\
\hline Voltage at MPP & $17 \mathrm{~V}$ \\
\hline Open Circuit Voltage & $21.7 \mathrm{~V}$ \\
\hline Current at MPP & $4.4 \mathrm{~A}$ \\
\hline Short Circuit Current & $4.8 \mathrm{~A}$ \\
\hline Power at MPP & $75 \mathrm{~W}$ \\
\hline
\end{tabular}

As observed, the inverter takes almost 0.3 seconds to attain a state where current and voltage are in phase. From 0 seconds to 0.1 seconds the MPPT tracks the optimum voltage to offer a voltage greater than the grid voltage. From 0.1 seconds to 0.3 seconds a stable steady state is attained where the current and voltage are brought inphase with nearly unity power factor.
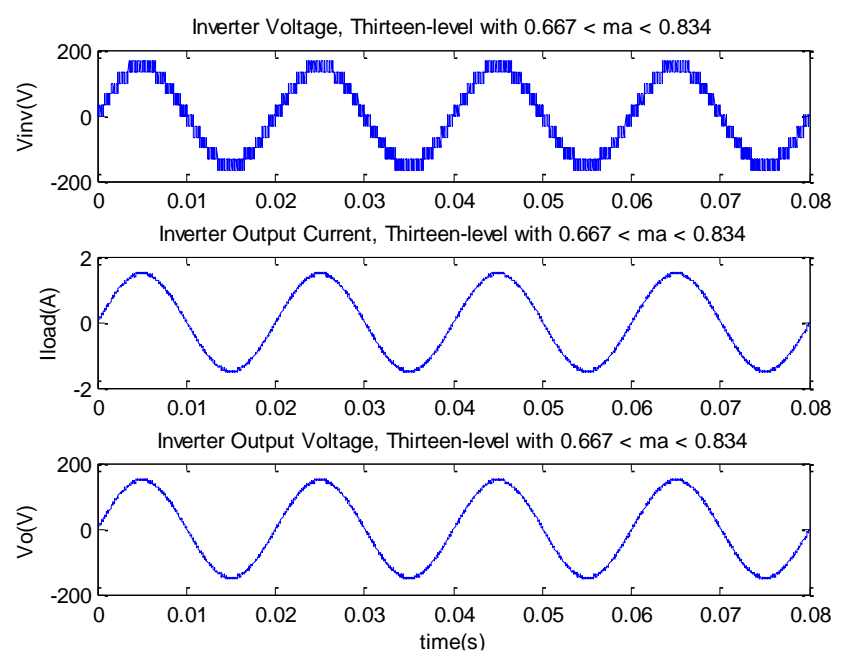

Figure 8: Inverter-Voltage, Output-Voltage and current for PiCHB with $\boldsymbol{M}_{\alpha}=\mathbf{0 . 7 5}$ above 0.67 and below 0.83
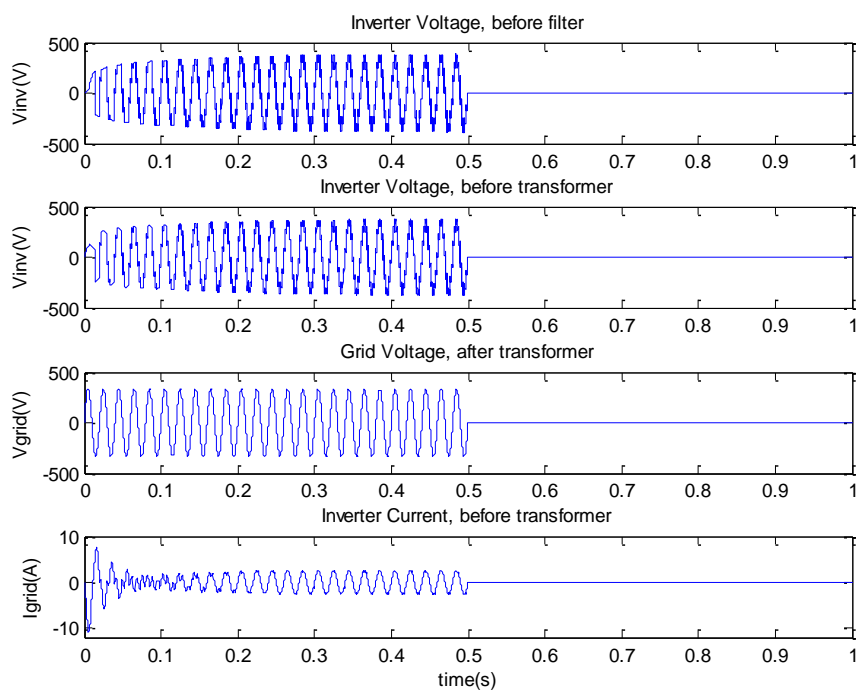

Figure 9: Time response PiCHB with MPPT mode when grid is disconnected

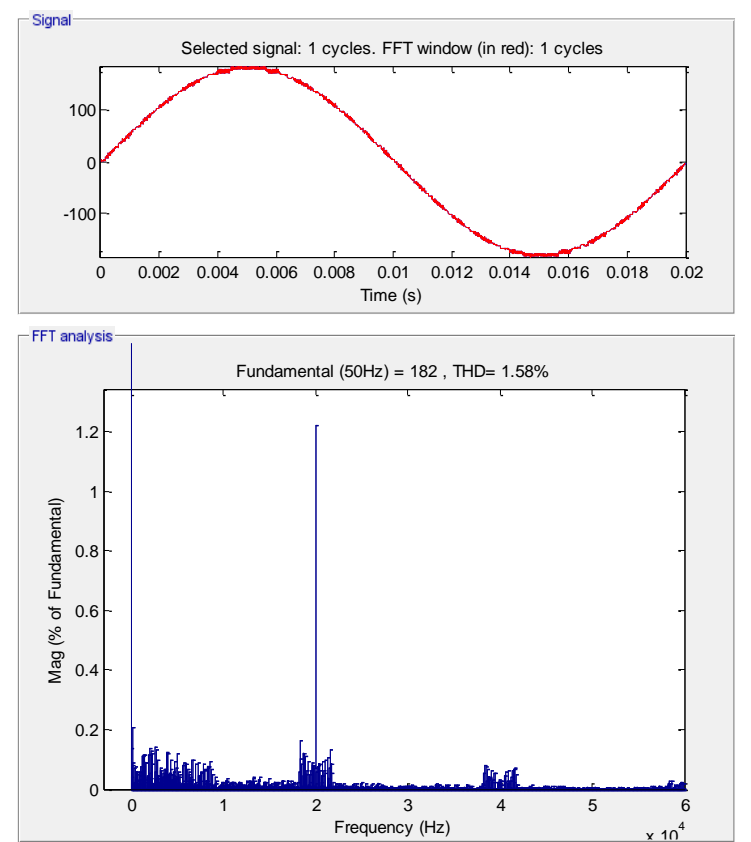

Figure 10: Output-Voltage THD

Figure 10 displays the output-voltage THD for the PiCHB when the modulation index is maintained between 0.83 and 1 . It is observed that the THD is significantly reduced to $1.58 \%$, while obtaining a sinusoidal output waveform. 

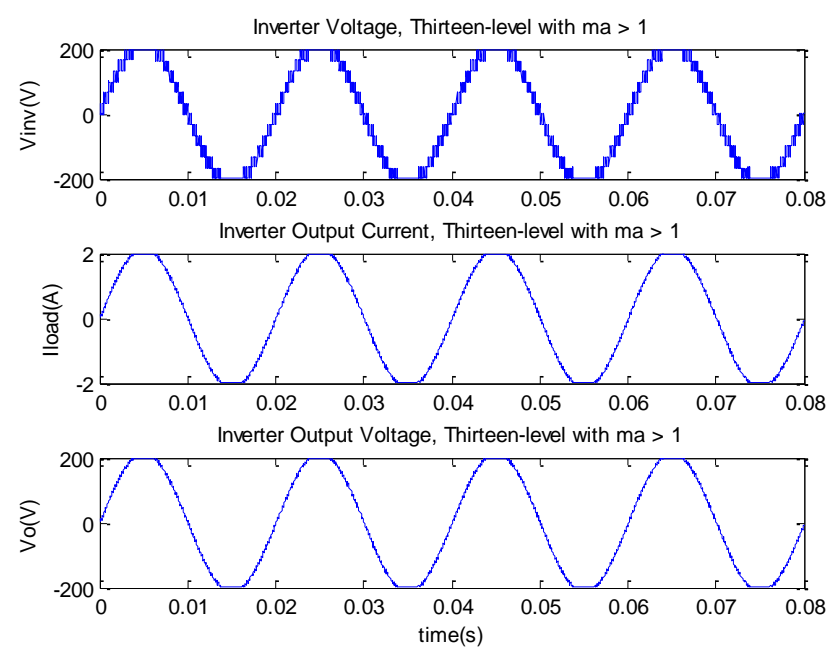

Figure 11: Inverter-Voltage, Output-Voltage and Current when $M_{a}=1.17$ exceeded 1

In addition, Figure 11 shows the output voltage and output current of the Pi-type inverter, which generated a chopped output voltage waveform at the output terminal, or, when the modulation index was above 1, with pre-filtered sinusoidal voltage and current at the load terminal. Here, the Modulation Index was set to be 1.17.

\section{Experimental Results}

The hardware platform was a TMS320F28335 DSP that drove a lab-prototype multilevel inverter aided by Texas Instrument's Code Composer Studio ${ }^{\mathrm{TM}}$ (CCStudio 3.1) and an ALTERA Cyclone II FPGA to implement the logic circuitry aided by the Quartus II 13.0sp1. The system used high switching frequencies and was implemented with a grid-tied PV application, Figure 12 Shows the experimental setup of the proposed inverter.

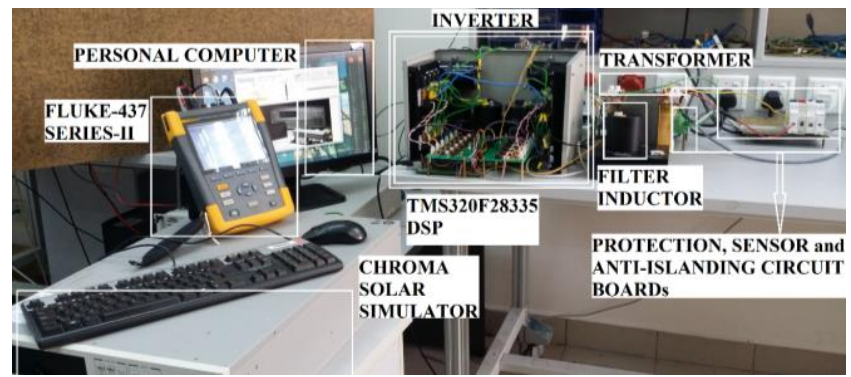

Figure 12: Experimental Setup

Figure 13 shows the output voltage and output current of the proposed inverter, which generated an eleven-level output voltage waveform at output terminal, or, when the modulation index was above 0.67 but below 0.83 , with pre-filtered sinusoidal voltage and current at the load terminal. Here, $M_{a}$ is set to be 0.75 .

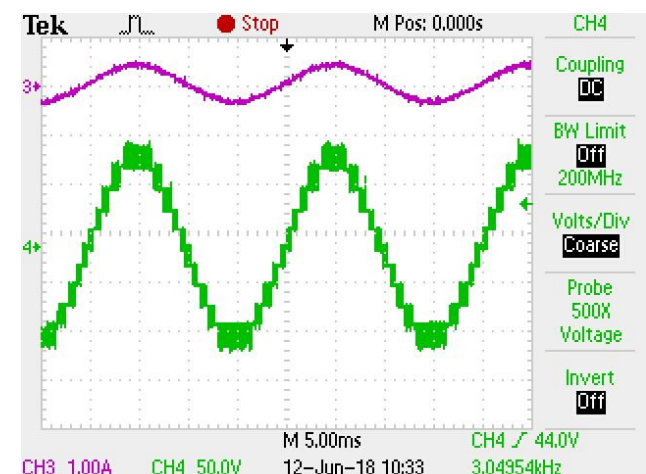

Figure 13: Output-Voltage and current for PiCHB with $\boldsymbol{M}_{\alpha}=\mathbf{0 . 7 5}$ above 0.67 and below 0.83

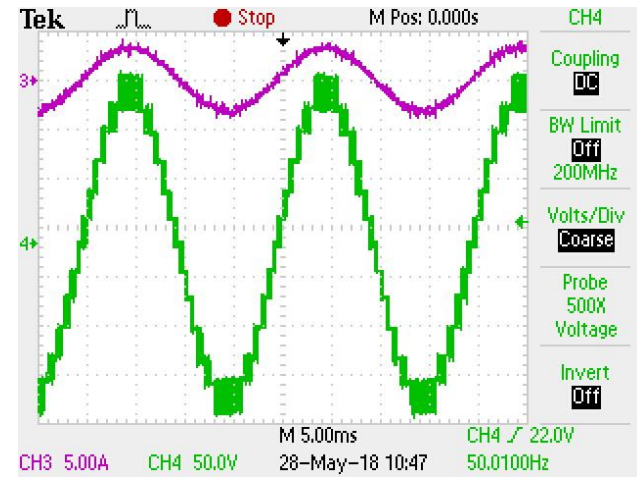

Figure 14: Output-Voltage and Current

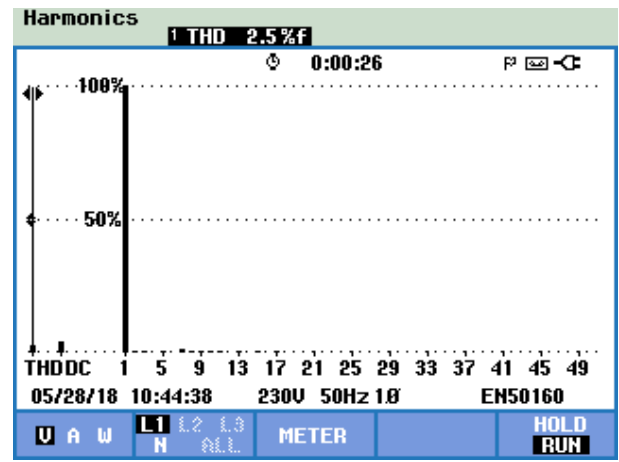

Figure 15: Output-Voltage THD

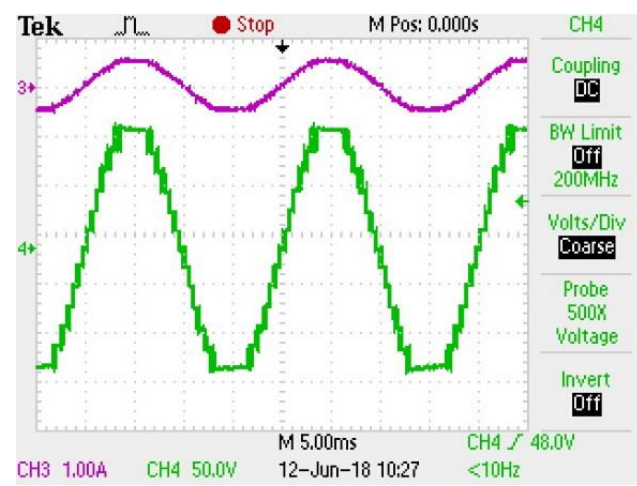

Figure 16: Output-Voltage and Current when $M_{a}=\mathbf{1} .17$ exceeded 1

Figure 14 shows the output voltage and output current of the Pi-type inverter, which generated a thirteen-level output voltage waveform at the output terminal, or, when the modulation index was above 0.83 but below 1.0, with pre-filtered sinusoidal voltage and current at the load terminal. Here, the Modulation Index was set to be 0.93 . Only when the inverter voltage was greater than the grid 
voltage, the power was injected into the grid. The current control technique was utilized to inject the near sinusoidal current generated by the Pi-type thirteen-level PV inverter. Figure 15 shows the output voltage THD. Figure 16 shows the output voltage and output current of the proposed inverter, which generated a chopped output voltage. Here, $M_{a}$ was set to be 1.17 .

\section{Conclusion}

This paper presented an overview of the existing current control techniques for grid-connection of single-phase PV inverter systems. In addition, a current control scheme has also been proposed for the grid-connection of single-phase cascaded H-bridge inverter topologies. The control for the cascaded H-bridge PV inverter relies on a PI current controller supported by a MPPT algorithm, a PWM scheme and an anti-islanding technique to attain a grid-tied PV system. This control system offers faster operation, improved efficiency, reduced THD and better output current quality. Here, this technique had been implemented on a Pi-type thirteen level inverter in a two stage grid connected PV system.

\section{Acknowledgement}

The authors would like to thank the financial and technical assistance provided by the University of Malaya, UM Power Energy Dedicated Advanced Centre (UMPEDAC), Higher Institution Centre of Excellence (HICoE) Program Research Grant, UMPEDAC - 2018 (MOHE HICOE UMPEDAC), Ministry of Education Malaysia, the High Impact Research Grant (H-16001-00-D000032), Fundamental Research Grant Scheme FP103-2018A, and IPPP Project under grant number RU007-2018 and RU012-2019.

\section{References}

[1] P. Nejat, F. Jomehzadeh, M. M. Taheri, M. Gohari, M. Z. A. J. R. Majid, and s. e. reviews, "A global review of energy consumption, $\mathrm{CO} 2$ emissions and policy in the residential sector (with an overview of the top ten $\mathrm{CO} 2$ emitting countries)," vol. 43, pp. 843-862, 2015.

[2] R. J. E. E. Inglesi-Lotz, "The impact of renewable energy consumption to economic growth: A panel data application," vol. 53, pp. 58-63, 2016.

[3] S. Chu and A. Majumdar, "Opportunities and challenges for a sustainable energy future," nature, vol. 488, no. 7411, p. 294, 2012.

[4] E. Kabir, P. Kumar, S. Kumar, A. A. Adelodun, and K.-H. Kim, "Solar energy: potential and future prospects," Renewable and Sustainable Energy Reviews, vol. 82, pp. 894-900, 2018.

[5] S. Kouro, J. I. Leon, D. Vinnikov, and L. G. J. I. I. E. M. Franquelo, "Grid-connected photovoltaic systems: An overview of recent research and emerging PV converter technology," vol. 9, no. 1, pp. 47-61, 2015.

[6] P. Rodriguez, C. Citro, J. I. Candela, J. Rocabert, and A. J. I. T. o. I. A. Luna, "Flexible grid connection and islanding of SPC-based PV power converters," vol. 54, no. 3, pp. 26902702, 2018.

[7] A. I. Putri, A. Rizqiawan, F. Rozzi, N. Zakkia, Y. Haroen, and P. A. Dahono, "A hysteresis current controller for grid-connected inverter with reduced losses," in 2016 2nd International Conference of Industrial, Mechanical, Electrical, and Chemical Engineering (ICIMECE), 2016, pp. 167-170: IEEE.

[8] F. Amrane, A. Chaiba, B. Francois, and B. Babes, "Real time implementation of gridconnection control using robust PLL for WECS in variable speed DFIG-based on HCC," in 2017 5th International Conference on Electrical Engineering-Boumerdes (ICEE-B), 2017, pp. 15: IEEE.

[9] M. S. Dawande, V. R. Kanetkar, and G. J. I. T. o. P. E. Dubey, "Three-phase switch mode rectifier with hysteresis current control," vol. 11, no. 3, pp. 466-471, 1996.

[10] M. P. Kazmierkowski and L. J. I. T. o. i. e. Malesani, "Current control techniques for threephase voltage-source PWM converters: A survey," vol. 45, no. 5, pp. 691-703, 1998.

[11] M. Castilla, J. Miret, J. Matas, L. G. de Vicuña, and J. M. J. I. T. o. I. E. Guerrero, "Linear current control scheme with series resonant harmonic compensator for single-phase gridconnected photovoltaic inverters," vol. 55 , no. 7 , pp. 2724-2733, 2008.

[12] J. Rodríguez, J. Pontt, C. Silva, P. Cortes, U. Amman, and S. Rees, "Predictive current control of a voltage source inverter," in 2004 IEEE 35th Annual Power Electronics Specialists Conference (IEEE Cat. No. 04CH37551), 2004, vol. 3, pp. 2192-2196: IEEE.

[13] P. Cortes, J. Rodriguez, C. Silva, and A. J. I. T. o. I. E. Flores, "Delay compensation in model predictive current control of a three-phase inverter," vol. 59, no. 2, pp. 1323-1325, 2011.

[14] J. Chen, A. Prodic, R. W. Erickson, and D. J. I. T. o. P. E. Maksimovic, "Predictive digital current programmed control," vol. 18, no. 1, pp. 411-419, 2003.

[15] F. Morel, X. Lin-Shi, J.-M. Rétif, B. Allard, and C. J. I. T. o. I. E. Buttay, "A comparative study of predictive current control schemes for a permanent-magnet synchronous machine drive," vol. 56, no. 7, pp. 2715-2728, 2009.

[16] J. Rodriguez et al., "State of the art of finite control set model predictive control in power electronics," vol. 9, no. 2, pp. 1003-1016, 2012.

[17] A. Amir, A. Amir, J. Selvaraj, N. A. Rahim, and A. M. Abusorrah, "Conventional and modified MPPT techniques with direct control and dual scaled adaptive step-size," Solar Energy, vol. 157, pp. 1017-1031, 2017/11/15/ 2017. 